\title{
Strength properties of plastic bottle bricks and their suitability as construction materials in Bangladesh
}

\section{Z Muyen, TN Barna, MN Hoque}

Department of Farm Structure \& Environmental Engineering, Bangladesh Agricultural University,

Mymensingh 2202, Bangladesh

\begin{abstract}
Among several waste reduction strategies, one that is gaining momentum is the development of construction materials that reuses a number of solid wastes. The 'bottle brick' is one such invention. Waste Polyethylene Terephthalate (PET) bottles packed with other dry solid wastes or sand and earth has been successfully used in a number of countries around the world. This study looked into the strength properties of waste PET bottles filled with fine sand. Five different sizes $(250,500,1250,1500$ and 2000ml) of waste PET bottle bricks were tested for compressive strength and the largest bricks gave a compressive strength of $17.44 \mathrm{MPa}$. The $1000 \mathrm{ml}$ bottle brick filled cubes with 9 and 12 bottles were prepared and tested. The 9 bottle brick filled cubes gave a compressive strength of $35 \mathrm{MPa}$ and the 12 bottle bricks filled cubes gave a compressive strength of $33.7 \mathrm{MPa}$. These bottle brick filled cylinders exhibited double the compressive strength of conventional concrete cylinders.
\end{abstract}

Key words: waste PET bottles, bottle brick, waste reduction, construction material, strength properties.

Progressive Agriculturists. All rights reserve

*Corresponding Author: zahida.muyen@bau.edu.bd

\section{Introduction}

With global solid waste generation rates rising faster than ever, urban development specialists warn that the growth will peak this century and will not start to decline without transformational changes in how we use and reuse materials. The World Bank's urban development specialists Daniel Hoornweg and Perinaz Bhada-Tata had placed the global Municipal Solid Waste (MSW) generation levels at approximately 1.3 billion tonnes per year in a 2012 report. They warned that the levels would increase to approximately 2.2 billion tonnes per year by 2025. This report also estimated the per capita global solid-waste generation rate would rise from more than 3.5 million tonnes per day in 2010 to more than 6 million tonnes per day in 2025 (Hoornweg and Bhada-Tata, 2012). The specialists warned that with 'business-as-usual' scenario, solid-waste generation rates will exceed 11 million tonnes per day by 2100 and population growth and urbanization will outpace waste reduction unless drastic measures are adopted (Hoornweg et al., 2013).

However, these estimates of global averages are very broad and they vary considerably by region, country, city and even within countries and cities. For example, Organisation for Economic Co-operation and Development (OECD) countries produce almost half of the world's waste, while Africa and South Asia regions produce the least waste. However, the OECD countries are better equipped in solid waste management than African or South Asian countries. Having said that, the conventional waste management techniques employed 


\section{Strength properties of bottle bricks}

in these countries have their own problems. The thousands of incinerators employed raise concerns about ash disposal and air pollution. Landfills, and uncollected waste, also contribute to climate change through the production of methane, a potent greenhouse gas. This scenario is even grim in developing countries of the African and South Asian regions. As a result a number of alternate tactics have been investigated to reduce and recycle waste. Reducing food waste with better storage and transportation, disposal fees and recycling programs, construction strategies that reuse materials and develop other building materials can lower waste generation.

Thinking along that line, a German national Andreas Froese invented the technique BI4PVS, which involves the use of disposable PET bottles, debris and earth as raw material for construction. PET bottles are completely filled with sand or soil or landfill dirt or mud and are used as bricks to construct houses and even water tanks. The technology was quickly adopted in different countries including Nigeria, South Africa, Norway, Philippines and India. His campaign till date has recovered and reused more than 300,000 PET bottles and has used these in more than 50 construction projects in Honduras, Columbia, Bolivia. When filled with soil or sand Froese's plastic bottles work as bricks and can be used in walls or pillars replacing conventional bricks. These walls can be of different sizes and orientations. Froese also measured the compression strength of his bricks; when filled with the weakest filling material e.g. sand; his plastic bottle walls can take up to $4.3 \mathrm{~N} / \mathrm{mm}^{2}$. The plaster made of clay or a cement mixture used to hold the bottles in place to build these walls carry two-thirds of the load while the bottles bear one-third. The roof of these bottle houses can be made of wood or corrugated metal sheets. Since these houses are made of locally sourced materials with much shorter construction periods, they are far less cheap compared to conventional houses. Houses built with such bricks have been labeled as "more durable, earthquake resistant, naturally insulated, low cost and environmentally friendly".
Moreover, they have so far been proved to be earthquake resistant (www.eco-tecnologia.com).Using this same technique, a Nigerian NGO 'Development Association for Renewable Energies' successfully built a two bedroom house entirely out of plastic bottles which is said to be "bullet and fireproof, earthquake resistant, and maintains a comfortable interior temperature of $64^{\circ} \mathrm{F}$ year round"(www.inhabitat.com). Raut et al.(2015) concluded that, in many ways such as time of execution, load capacity, flexibility, waste and cost reduction and energy efficiency, plastic bottle bricks can be better compared to some conventional building materials such as brick, concrete and ceramic blocks.

Shoubi et al. (2013) reported that being lighter, plastic bottle walls can be better against earthquakes; due to the compaction of filling material in the bottles, they are 20 times more load resistant than conventional bricks; these filling materials also make these walls bullet proof. These walls can also support themselves. When these bottles are filled with sand, gravel and cork or wood particles, these bottle walls also have great insulating capability. These walls can absorb abrupt shock loads; being non-brittle they produce much less construction waste compared to conventional bricks. They also reported that compared to brick and concrete block walls, plastic bottle walls cost $75 \%$ less. Raut et al.(2015) compared the cost of a $10 \mathrm{~m}^{2}$ brick and masonry wall to a plastic bottle masonry wall and concluded that the bottle wall cost roughly $50 \%$ less than the brick wall. Given its wide range of benefits over conventional construction materials, Ramaraj and Nagammal (2014) believe that possibilities of using PET bottles as structural members, foundation, retaining walls and secondary elements like street furniture, road dividers, pavements and other landscape elements should be explored. There should be extensive research and encouragement from different Government and non-Government sectors to publicize and popularize this non-conventional construction material. 
Bangladesh currently has a huge solid waste management problem with unsightly dumping grounds across the country. Moreover, an ever increasing number of people migrating to the cities in search of a better future have led to the development of slums in the already highly populated city landscapes. Houses built with bottle bricks can offer them low cost alternatives which could also provide a number of other benefits. With that in view, this paper looked at the compressive strength of waste PET bottle bricks, bottle brick cubes and compared them with conventional bricks. A comparative cost analysis was also done to assess the cost effectiveness of bottle bricks to assess the overall suitability of this technology in Bnagladesh.

\section{Materials and Methods}

\section{Preparation of plastic bottle bricks}

Waste PET bottles of different sizes were collected and washed. Fine sand was filled into these bottles in three layers; each layer compacted with 20 blows usingtamping rod.

\section{Preparation of plastic bottle brick filled cylinders}

The cement mortar for the cylinders were made of 1:3(Ordinary Portland Cement: sand)by weight with a water cement ratio of 0.6.The size of the cylinder mold was $150 \mathrm{~mm}$ in diameter and $300 \mathrm{~mm}$ in length. The molds were oiled with medium viscosity oil before the mortar was poured in. The mortar was filled in four layers each approximately $75 \mathrm{~mm}$ high. After the first two layers a $1000 \mathrm{ml}$ sand filled plastic brick was inserted into the middle of the mold.

Each layer was rammed 35 times with evenly distributed strokes. The molds were covered with wet mats. The cylinders were removed from the molds after 24 hours and were immersed in water for the final curing. The test was conducted at 3, 7 and 28 days.

\section{Preparation of plastic bottle brick filled cubes}

Wooden cubes $(25.4 \mathrm{~cm} \times 25.4 \mathrm{~cm} \times 25.4 \mathrm{~cm})$ were made to prepare the desired bottle brick inserted cement mortar cubes. The cement mortar for the cubes were made of 1:3 (Ordinary Portland Cement: sand)by weight with a water cement ratio of 0.6 . A $2 \mathrm{~cm}$ thick layer of mortar was placed in the mold which was compacted with 20 even blows of the tampering rod. Once the first layer had been compacted, three same sized $(500 \mathrm{ml})$ sand filled plastic bottles were placed on this first layer of mortar. Then another layer of mortar is placed in the mold covering the first layer of bottles evenly. Approximately 10 blows of the tampering rod were given. The second and third layers of bottles were placed similarly with cement mortar in between the bottles. The step by step process in which a total of nine bottles are inserted into the cube mold is shown in Figure 1. A second set of cubes were prepared in the same way but with twelve $500 \mathrm{ml}$ bottle bricks. Figure 2 shows the step by step process.

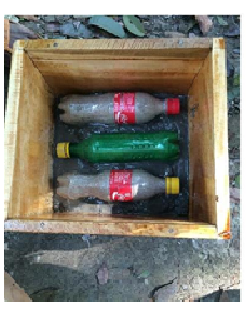

Layer 1

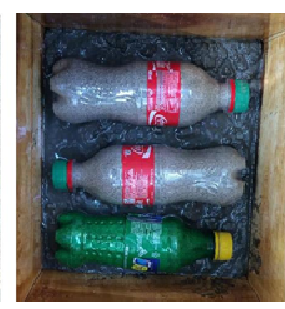

Layer 2

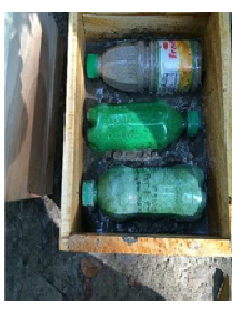

Layer 3
Figure 1. Making plastic bottle brick filled cement mortar cubes using nine $500 \mathrm{ml}$ bottles.

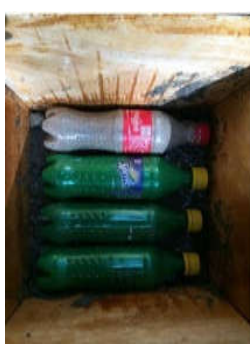

Layer 1

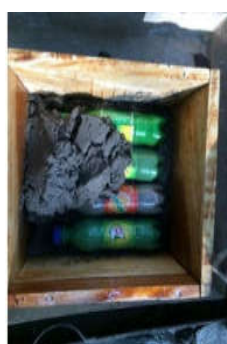

Layer 2

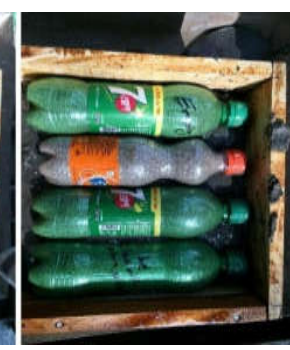

Layer 3
Figure 2. Making plastic bottle brick filled cement mortar cubes using twelve $500 \mathrm{ml}$ bottles.

\section{Compressive strength tests for plastic bottle bricks}

A Digital Display Compression testing machine was used for compression test. The brick was placed 
between loading plates of the machine. The bottles didn't break but did deform. The load was increased until the reading showed a sudden drop of force. The load at which it started to drop was recorded as the maximum load. Figure 3 shows the testing arrangement and the bottle bricks after the test.
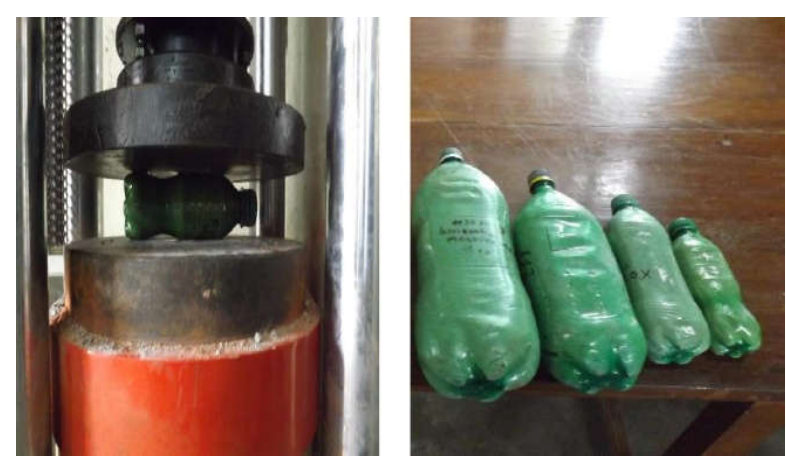

Figure 3. Compression test for plastic bottle bricks and deformed bricks after the test.

\section{Compressive strength tests for plastic bottle brick filled cylinders}

The cylinder was placed onto the flat surface of a circular pressure plate of the compression testing machine. The load was applied through the moveable plate acting on the full sectional area of the cylinder. The maximum load at the point of ultimate failure was recorded. Figure 4 shows the cylinder during the test and after complete failure.

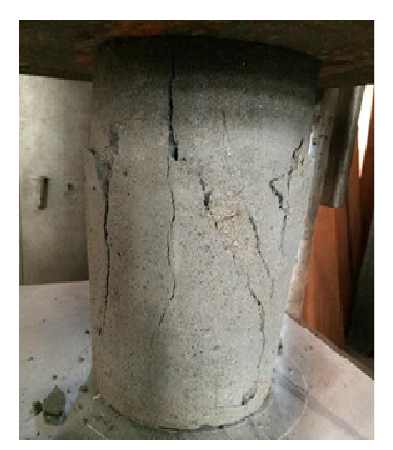

Figure 4. Plastic bottle filled cylinder during compressive strength test and after complete failure.

\section{Split tensile strength tests for plastic bottle brick filled cylinders}

The cylinder is positioned to ensure that lines marked on the end of the cylinder are vertical and the projection of the plane passing through these two lines intersects the center of the plate. The load is applied without shock and was increased continuously at the rate to produce a split tensile stress of approximately 1.4 to $2.1 \mathrm{~N} / \mathrm{mm}^{2} / \mathrm{min}$, until no greater load can be sustained. The maximum load applied was recorded. Figure 5 shows the assembly and the failure after the maximum load had been applied.
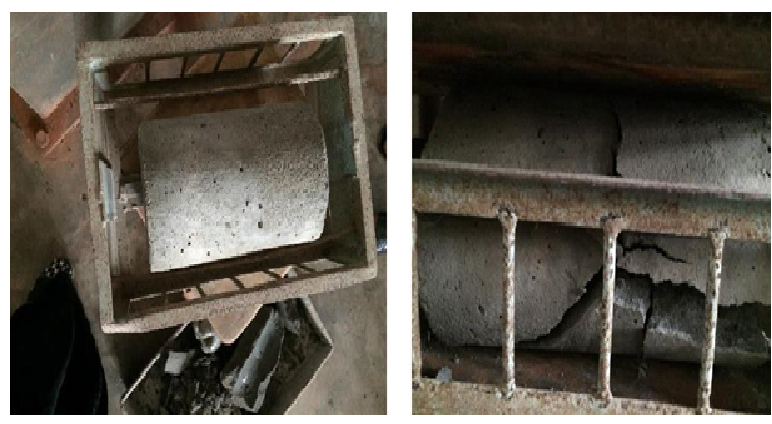

Figure 5. The plastic bottle brick filled cylinder assembled for split tensile strength test and the cylinder after failure.

\section{Compressive strength tests for plastic bottle brick filled cubes}

Once the cubes underwent 28 days curing, their compressive strength was tested using the Universal Testing Machine. Figure 6 shows the cubes being tested and the cubes at failure.
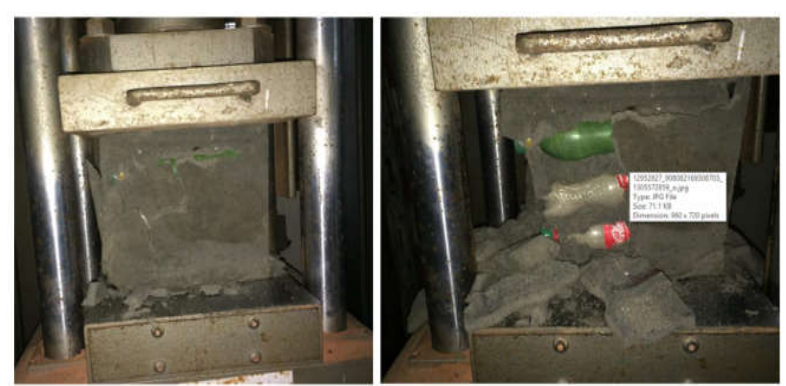

Figure 6. Plastic bottle filled cubes during compressive strength test and after complete failure. 


\section{Results and Discussion}

The compressive strength of bottle bricks increased with the size of the bottle as shown in Figure 7. Depending on the structure to be constructed and the anticipated load, plastic bottle bricks offer a range of options.

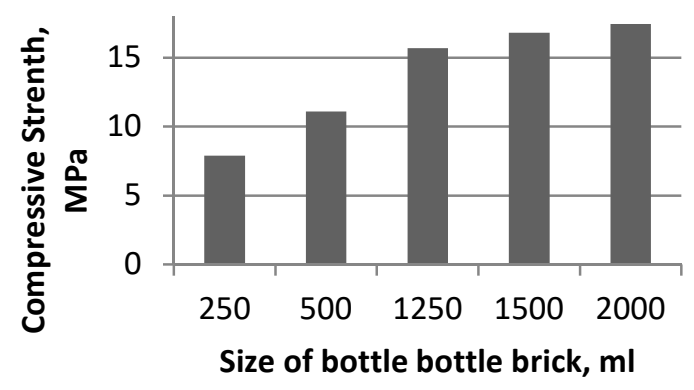

Figure 7. Compressive strengths of different sized bottle bricks

Standard concrete cylinders made of picked jhama brick chips using 1:3:6 proportion (cement: fine aggregate: coarse aggregate) after 28 days curing obtained 10-12MPa of compressive strength. As Table 1 shows, the sand filled $1000 \mathrm{ml}$ plastic bottle brick cylinders gave 19.9MPa compressive strength after 28 days curing. Table 2 shows the 28 day compressive strengths for cubes made with bottle brick insertions. These cubes with considerable compressive strengths can easily be used as substitutes for concrete blocks in low cost construction.

Table 1. Compressive and Splitting Strengths for sand filled 1000 mlplastic bottle brick cylinders.

\begin{tabular}{|c|c|c|}
\hline Curing period & $\begin{array}{l}\text { Compressive } \\
\text { strength, MPa }\end{array}$ & $\begin{array}{l}\text { Splitting } \\
\text { Strength, } \\
\text { MPa }\end{array}$ \\
\hline 3 days & 10 & 0.55 \\
\hline 7 days & 12.4 & 0.82 \\
\hline 28 days & 19.9 & 1.7 \\
\hline
\end{tabular}

Table 2. Compressive Strengths for 9 and 12 bottles filled cubes after 28 days of curing

\begin{tabular}{|c|c|c|}
\hline $\begin{array}{l}\text { Curing } \\
\text { period }\end{array}$ & $\begin{array}{l}\text { Number of } \\
\text { bottles }\end{array}$ & $\begin{array}{l}\text { Compressive } \\
\text { strength, MPa }\end{array}$ \\
\hline 28 days & 9 & 35 \\
\hline 28 days & 12 & 33.7 \\
\hline
\end{tabular}

Figure 8is the view of the column constructed with the sand filled bottle bricks and the part of the wall. A complete house could not be built due to lack of available space and time, but as figure 8 shows, columns and walls can easily be constructed with the bottle bricks made in the laboratory. Depending on the purpose and size of the construction, different sized bottle bricks having varying strengths can be used. Even bottle brick filled cylinders and cubes can be used as building blocks to construct these columns and walls as necessary.

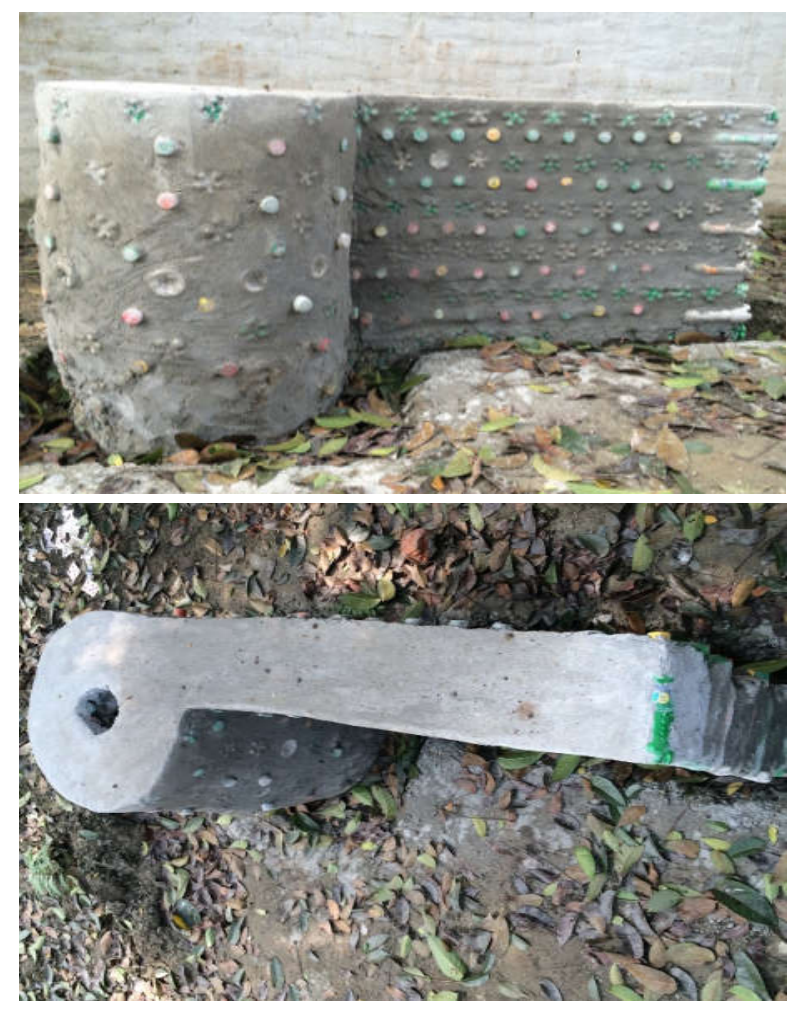

Figure 8. (i) A column and part of a wall constructed with plastic bottle bricks; (ii) View from the top of the column and the wall. 
This technique has been widely accepted as the 'next thing' in low cost housing in many countries worldwide. The following section includes a cost calculation and comparison to see how these bottle bricks compare with the traditional bricks in Bangladesh.

Cost calculation:

Cost of making a single bottle brick is calculated and compared with the cost of a single brick.

Cost of waste PET bottle: Cost of waste PET bottle= $\mathrm{Tk} .8 / \mathrm{kg}$.

Avg. wt. of a $500 \mathrm{ml}$ PET bottle $=28 \mathrm{gms}$.

No. of bottles in $1 \mathrm{Kg}$. $=(1000 \div 28) \sim 36$

Cost of $1500 \mathrm{ml}$ PET bottle $=$ Tk. $8 \div 36=$ Tk. 0.22

Cost of sand to be filled:Cost of $3 \mathrm{~m}^{3}$ sand $=$ Tk. 450

Cost of $1 \mathrm{~m}^{3}$ sand= Tk. 150

Bulk density of sand is $1.28 \mathrm{ton} / \mathrm{m}^{3}$

So, weight of $1 \mathrm{~m}^{3}$ sand $=1280 \mathrm{~kg}$

Cost of $1 \mathrm{~kg}$ sand $=150 \div 1280=$ Tk. 0.11718

Total cost of bottle brick: Avg. wt. of empty bottle= $28 \mathrm{gms}$

Avg wt. of bottle with sand $=890 \mathrm{gms}$

So, wt. of sand in 1 bottle $=862 \mathrm{gms}$

Cost of sand used in 1 bottle $=0.862 \times 0.11718=\mathrm{Tk}$. 0.10

Labor cost $=$ Tk. 300 per day per laborer

A total of 150 bottles can be filled in one day by one laborer

Cost of filling 1 bottle $=$ Tk. 2.00

Therefore total cost of a bottle brick $=$ cost of empty bottle + cost of sand + cost of labor

$=\mathrm{Tk} .(0.22+0.10+2.00)$

$=\mathrm{Tk} .2 .32$

Calculation of Profit: Cost of a brick $=$ Tk. 7.5

Cost of a bottle brick $=\mathrm{Tk} .2 .32$

So, profit $=$ Tk. $(7.5-2.32)=$ Tk.5.18

\section{Conclusion}

This technique of using waste PET bottles as bricks has become popular in low income communities around the world. In the current study, the bottle bricks were found to be stronger than conventional bricks and concrete cylinders. These bottle bricks are also Tk. 5.18 cheaper than the conventional bricks. Considering the strength and the relatively low cost of construction, they can very successfully become the next construction material of choice for Bangladesh too. These houses would be a positive change in our urban fringe and slum areas' landscape.

\section{Reference}

Eco Technologiawww.eco-tecnologia.com accessedon March 23, 2016.

Hoornweg D, Bhada-Tata P (2012). What a Waste: A Global Review of Solid Waste Management.Accessedfromsiteresources.worldban k.org/.../336387.../What_a_Waste2012_Final.pdf

Hoornweg D, Bhada-Tata P, Kennedy C (2013). Environment: Waste production must peak this century. Accessed from http:/www.nature.com/news/ environment-waste-production-must-peak-this-century1.14032. www:inhabitat.com (http://inhabitat.com/ africas-first-plastic-bottle-house-rises-in-nigeria/ nigeria-bottle-house-1/). Accessedon March 23, 2016.

Ramaraj A, Nagammal J (2014). Exploring the Current Practices of Post Consumer PET Bottles and the Innovative Applications as a Sustainable Building Material-A Way Ahead. 30th INTERNATIONAL PLEA CONFERENCE16-18 December 2014, CEPT University, Ahmedabad.

Raut A, Patel MS, Jadhwar NB, Khan U, Dhengare SW (2015). Investigating the Application of Waste Plastic Bottle as a Construction Material- A Review. Journal of The International Association of Advanced Technology and Science, 16.

Shoubi MV, Shoubi MV, Barough AS (2013). Investigating the Application of Plastic Bottle as a Sustainable Material in the Building Construction. 
Muyen et al. (2016), Progressive Agriculture 27 (3): 362-368

International Journal of Science, Engineering and Technology Research, 2(1): 28-34. 